\title{
SIGNIFICADOS ATRIBUÍDOS AO LAZER NA TERCEIRA IDADE: OBSERVAÇÃO PARTICIPANTE EM ENCONTROS MUSICAIS
}

\author{
1 Fábio Francisco de Araujo \\ ${ }^{2}$ Angela da Rocha
}

\section{RESUMO}

Este estudo buscou investigar os significados atribuídos ao lazer em grupo por consumidores idosos. O estudo parte de uma revisão da literatura sobre consumo e lazer na Terceira Idade, enfatizando a passagem de uma perspectiva negativa, baseada em restrições ao consumo, para uma visão mais positiva do envelhecimento, nos estudos mais recentes. A pesquisa utilizou métodos oriundos da etnografia urbana, em particular a observação participante e as entrevistas em profundidade, adequados à natureza do fenômeno investigado. Foi escolhido, para a realização do trabalho de campo, um grupo de encontros musicais que se reúne no Palácio do Catete, no Rio de Janeiro. No decorrer da observação participante foram realizadas entrevistas informais com participantes, registradas em diário de campo, além do uso de fotografias e vídeos. Ao final da observação participante, que durou seis meses, foram realizadas 16 entrevistas em profundidade, gravadas e transcritas. Utilizaram-se técnicas de análise de discurso. Seis diferentes categorias de significados emergiram do trabalho de campo: (1) significado hedônico; (2) espaço de sociabilidade; (3) nostalgia; (4) qualidade de vida; (5) (re)construção da identidade; e (6) aprendizado. Verificou-se que a imersão nessa atividade de lazer permitiu aos idosos participantes produzirem uma ressignificação da Terceira Idade.

Palavras-chave: Lazer, Consumidores idosos, Música.

\section{MEANINGS ATTACHED TO SPORTS IN THE ELDERLY: NOTE PARTICIPANT IN MUSICAL ENCOUNTERS}

\begin{abstract}
This study aimed at investigating the meanings associated to leisure by a group of senior consumers. The study departs from the literature con consumption and leisure for senior individuals, showing the transition between a negative view, based on the restrictions to consumption, to a more positive view of aging, supported by recent studies. The research used methods from urban ethnography, especially participant observation and in-depth interviews, more adequate to the nature of the phenomenon under investigation. Fieldwork was carried out with a group of senior consumers that meet at the Palácio do Catete, in Rio de Janeiro. During participant observation informal interviews were conducted with participants, which were registered in field notes, in addition to photography and videos. At the end of the participant observation, which lasted six months, 16 in-depth interviews were conducted, which were recorded and transcripts made of each. The analysis used discourse analysis techniques. Six different categories of meanings emerged from the field: (1) hedonism; (2) sociability; (3) nostalgy; (4) quality of life; (5) identity (re)construction; and (6) learning. It was found that the immersion in this leisure activity allowed senior participants to achieve a new meaning for aging.
\end{abstract}

Keywords: Leisure, Senior consumers, Music.

${ }^{1}$ Doutor em Administração de Empresas pela Pontifícia Universidade Católica - PUC, Rio de Janeiro, (Brasil). Professor Adjunto no Curso de Administração da Universidade Federal Fluminense - UFF, Rio de Janeiro, Brasil. E-mail: fabiofdearaujo@gmail.com

2 Doutora em Dirección de Empresas pela IESE Business School - Universidad de Navarra, (Espanha).

Professora Associada do IAG Escola de Negócios da Pontifícia Universidade Católica - PUC, Rio de Janeiro.

E-mail: amc.darocha@gmail.com 


\section{INTRODUÇÃO}

O segmento de consumidores que chega à Terceira Idade constitui um contingente cada vez maior, indicativo da grande alteração demográfica que vem ocorrendo não só no Brasil como em diversos outros países do mundo, entre os quais economias emergentes como Coreia do Sul e China. Uma das razões para o fenômeno é a longevidade, que vem, cada vez mais, acompanhada de vitalidade, energia e disponibilidade de recursos financeiros para o consumo e o lazer (Fox, Roscoe \& Feigenbaum, 1984). De acordo com Ballstaedt (2007), o aumento da expectativa de vida traz consigo a possibilidade de aproveitar a vida de forma mais produtiva e saudável. Nesse sentido, o envelhecimento da população abre caminho para o surgimento de um novo segmento de consumidores com valores, comportamentos, estilos de vida e necessidades específicos.

Os serviços relacionados ao lazer são aqueles que mais despertam o interesse da população de Terceira Idade (Ballstaedt, 2007). Os membros desse segmento são também chamados de idosos, maduros, sêniores ou velhos. Neste trabalho usamos indistintamente os termos Terceira Idade e idosos. Doll (2007) ressalta que as atividades de lazer em grupo são frequentemente usadas pelos idosos para preencher o vazio deixado pela aposentadoria.

Este estudo buscou investigar os significados atribuídos ao lazer em grupo por consumidores idosos. A questão principal que norteou a pesquisa foi definida de forma bastante abrangente, como se segue: Quais são os significados atribuídos a determinadas atividades de lazer em grupo por consumidores de Terceira Idade?

A contribuição teórica do trabalho pode ser entendida sob três aspectos. Primeiro, o estudo traz efetiva contribuição para o entendimento do comportamento de uma parcela praticamente ignorada de consumidores - os de Terceira Idade -, como atestam inúmeros autores (por exemplo, Ballstaedt, 2007; Esteves, 2010; Moschis, 2003; Myers \& Lumbers, 2008). Segundo, a pesquisa se aprofunda especificamente na forma pela qual as experiências de lazer adquirem significado à luz da construção e fortalecimento de relações sociais e de amizade em atividades de grupo. Para Alves (2007), a relação entre velhice e redes sociais é um tema apenas tangenciado na literatura. Terceiro, o lazer dos idosos encontra-se em uma etapa de transição, dado que muitos chegam à Terceira Idade em boas condições físicas e de saúde, o que não costumava ocorrer até pouco tempo atrás (Doll, 2007). Assim, a quase totalidade dos estudos existentes trata dos impedimentos e barreiras ao lazer dos idosos, focando suas deficiências, enquanto o presente estudo enfatiza a vivência do lazer por idosos aptos do ponto de vista físico e mental. Pesquisas recentes na disciplina de marketing sublinham que os idosos realizam suas escolhas de consumo a partir de suas próprias perspectivas e interesses, observando que o comportamento do consumidor idoso é fortemente impactado pela experiência compartilhada com amigos e outros idosos com quem interage mais diretamente. Nesse sentido, o grupo de referência também pode ser identificado como uma fonte relevante para escolhas e tomada de decisões de consumo (Alves, 2007; Barnhart \& Peñaloza, 2013; Myers \& Lumbers, 2008).

\section{REFERENCIAL TEÓRICO}

O lazer ocupa espaço relevante nas sociedades contemporâneas. No entanto, a própria noção de lazer não se manifestou em todas as sociedades no passado e, quando ocorre, seu significado pode diferir substancialmente. Mesmo nas sociedades contemporâneas, a divisão do tempo entre o que é lazer e o que não é varia muito em função do grupo etário e da cultura em que se insere o indivíduo (Araujo, Rocha, Chauvel \& Schulze, 2013). O lazer pode ser compreendido como um conjunto de ocupações, individuais ou coletivas, em que o indivíduo pode se dedicar por sua livre vontade "seja para repousar, seja para divertir-se, recrear-se e entreter-se ou ainda para desenvolver sua informação ou formação desinteressada, sua participação social voluntária ou sua livre capacidade criadora" (Dumazedier, 1973, p. 34).

É difícil falar dos significados atribuídos ao lazer sem citar Provonost (2011) e sua Introdução à Sociologia do Lazer. O autor aponta que uma consideração dos estudos sociológicos sobre lazer mostra que o mesmo se configura "como um domínio secundário da vida humana", predominando valores relacionados à família, ao trabalho e à educação. No entanto, apesar da posição inferior na hierarquia de valores das sociedades contemporâneas, quando se trata do "domínio da ação", o lazer se manifesta "como atividade agradável, fortemente valorizada, se não a preferida" (p. 31). Lazer é equacionado a "felicidade", "prazer", "direito adquirido" e até mesmo visto como “imprescindível”. É visto ainda como forma de evasão das dificuldades e sofrimentos da vida pelos socialmente excluídos, os de nível social mais baixo e os idosos.

Ao atingirem idade mais avançada, os consumidores passam a preocupar-se com a utilização de seu tempo e procuram atividades que preencham o tempo livre e que constituam novas experiências. 
Muitos idosos se dão conta de que "há muito para se viver" e procuram participar do maior número possível de atividades em seus últimos anos de vida (Neugarten, 1968).

Contudo, segundo Crawford, Jackson e Godbey (1991), as decisões de consumo de lazer na Terceira Idade estão relacionadas às barreiras encontradas nos níveis intrapessoal, interpessoal e estrutural. Barreiras estruturais representam as restrições, tais como fatores intervenientes entre a preferência de um consumidor e sua participação em determinado tipo de lazer, estando associadas a estágio no ciclo de vida, recursos financeiros, clima, horário, existência de oportunidade e outras mais que impedem o consumidor de participar de atividade de sua preferência. Barreiras intrapessoais incluem o estado psicológico dos consumidores e características pessoais que interagem com as preferências de lazer. Barreiras intrapessoais se manifestam por estresse, depressão, ansiedade, religiosidade e outras avaliações subjetivas do quão adequada para o próprio consumidor é a atividade. Barreiras interpessoais resultam da interação pessoal, particularmente do relacionamento do consumidor com outros. No Brasil, o estudo empreendido por Diniz e Motta (2006) apontou a existência de oito fatores restritivos ao consumo de lazer por idosos: receios, falta de apoio interno e externo, medo de transporte, falta de interação social, falta de companhia, desinteresse pela experiência, falta de recursos financeiros e de tempo.

Apesar de ao menos parte da população de Terceira Idade apresentar algumas restrições para usufruir de serviços de entretenimento e lazer (Crawford, Jackson \& Godbey, 1991; Cuddy, Norton $\&$ Fiske, 2005), estudos mais recentes sugerem que esses consumidores também podem estar mais abertos a experimentar novidades nessa fase da vida, como viagens a lazer (Horneman, Carter, Wei \& Ruys, 2002) e a praticar atividades que permitam mais convivência com amigos, independência da família, aprendizado e autorrealização (Ballstaedt, 2007; Burnett-Wolle \& Godbey, 2007; Fox, Roscoe \& Feigenbaum, 1984; Myers \& Lumbers, 2008). A constatação dessa tendência pode marcar uma nova forma de enxergar os consumidores de Terceira Idade, não apenas a partir de suas limitações.

Alves (2007) observou os idosos a partir de suas redes de relações sociais e familiares, sublinhando o valor da amizade e a importância da sociabilidade para construção da identidade desses indivíduos. As relações familiares são marcadas pela ideia de obrigação e responsabilidade, enquanto a amizade tem um papel especial por se encontrar na esfera da escolha pessoal. Os idosos que se aproximam compartilham gostos, estilos de vida, uma forma comum de se expressar e expor sentimentos. Essa construção de afinidades lhes permite avançar nas negociações internas de suas relações, gerando intimidade e reciprocidade e estabelecendo laços de ajuda e de conforto emocional.

A disciplina de marketing tem dado alguma atenção ao idoso como consumidor. Destaca-se, entretanto, que os estudiosos de marketing têm contribuído para a construção da noção de Terceira Idade como se o idoso estivesse em uma posição marginalizada e desvalorizada. Por exemplo, o Modelo de Ciclo de Vida (FLC) de Wells e Gubar (1966) reproduz os estereótipos negativos da velhice, isolamento e solidão anteriormente avançado por Cumming e Henry (1961), ao intitular fases da velhice como "ninho vazio" e "sobrevivente solitário". Mais tarde, como nas atualizações para o modelo de Gilly e Enis (1982) e Murphy e Staples (1979), os consumidores idosos continuaram a ser segmentados como consumidores solteiros ou casados, em vez de classificados como membros do grupo, o que pode se dever ao foco sobre o consumo das famílias na segmentação de consumidores adultos (Peter \& Olson, 2009).

Os primeiros estudos sobre as práticas de consumo na Terceira Idade - assim como parte importante da literatura subsequente - focavam as restrições desse grupo para realizar plenamente o seu papel de consumidor. Alexandris e Carroll (1997) relacionam tais restrições ao efeito idade e ao ciclo de vida, os quais se revelam como interferências peculiares ao contexto de decisão do consumidor. Para Fleischer e Pizam (2002), as restrições físicas e intrapessoais aumentam significativamente com a idade, pois, com o avanço da idade, mais deterioradas tornam-se as condições de saúde. Essas transformações naturais podem afetar mobilidade, flexibilidade, elasticidade, força, visão e audição, o que impacta suas relações sociais, profissionais e familiares e sua forma de consumir (Pak \& Kambil, 2006). De acordo com o estudo de Hoeymans et al. (1997), as pessoas idosas tendem a perder suas habilidades funcionais com o passar dos anos, mas a saúde e a capacidade de avaliação do contexto não necessariamente diminuem com o passar do tempo. Mesmo assim, embora parte dos idosos apresente limitações físicas, não se pode generalizar essa condição para toda a população da Terceira Idade. No entanto, a maior parte dos produtos anunciados e vendidos especificamente para os idosos ainda está relacionada à ideia de incapacidade de locomoção ou condição física limitada (Araujo, Casotti, Silva, \& Pessôa, 2015).

Os estudos na literatura que abordam limitações dos idosos abarcam diferentes temas. Por exemplo, Gilly e Zeithaml (1985) publicaram um estudo no Journal of Consumer Research em que discutem a adoção de recursos tecnológicos pelos consumidores idosos. Os resultados apontam no sentido de que os idosos têm mais dificuldades de interagir com 
inovações, bem como apresentam ritmo diferente para utilizar tais recursos. Já o estudo de Mattila et al. (2003) buscou conhecer o comportamento dos idosos em relação a serviços bancários, notadamente no que diz respeito à introdução dos serviços de autoatendimento. Os resultados mostram que os idosos, sempre que possível, optam por dispensar o autosserviço e preferem ser atendidos ou assistidos por funcionários, em razão das dificuldades de interação com equipamentos automatizados. Kennett, Moschis e Bellenger (1995) observaram dificuldades parecidas em relação aos serviços financeiros disponíveis para investimento de sua renda discricionária.

Além disso, segundo Schewe e Carlson (2003), os pesquisadores de marketing têm negligenciado realizar uma segmentação mais precisa em função da idade, pois, apesar de um indivíduo ser considerado idoso, ele pode ter necessidades diferenciadas com relação a outros também considerados idosos. Isso decorre de diversas razões, entre as quais as diferentes faixas de idade abarcadas pela Terceira Idade e, até mesmo, diferenças de geração.

Estudos de marketing mais recentes sobre a tomada de decisão dos consumidores idosos (por exemplo, Cole et al., 2008; Lambert-Pandraud \& Laurent, 2010; Nasco \& Hale, 2009; Pettigrew et al., 2005; Williams \& Drolet, 2005) se baseiam ainda na suposição de que a velhice afeta a forma como as pessoas consomem, o que não é necessariamente verdade, como observam Barnhart e Peñaloza (2013). Ao suporem que a velhice modifica o consumo, os pesquisadores deixam de considerar e questionar de que maneira os idosos compreendem a velhice e como consomem a partir de sua própria visão enquanto sujeitos ativos de consumo. Assim, Barnhart e Peñaloza (2013) defendem que é preciso entender como os idosos realizam suas escolhas de consumo a partir de suas próprias perspectivas e interesses.

A pesquisa de Barnhart e Peñaloza (2013) investigou a prática e o discurso do consumo da Terceira Idade em relação à visão de familiares e cuidadores dos idosos sobre seu consumo. Apesar da influência familiar, o comportamento do consumidor idoso é fortemente impactado pela experiência compartilhada por seus amigos e por pessoas com quem interage nos grupos de que participa. Nesse sentido, o grupo de referência também foi identificado como uma fonte relevante para escolhas e tomadas de decisão de consumo e como alternativa à influência de familiares e de cuidadores. Assim, os idosos tendem a priorizar a experiência de iguais (amigos ou outros idosos) com quem se identificam, resistindo à opinião de familiares e cuidadores.

\section{METODOLOGIA}

A presente pesquisa teve como objetivo principal compreender os significados atribuídos ao lazer em grupo por consumidores de Terceira Idade com outros indivíduos da mesma faixa etária. Entre as diversas opções de lazer disponível, optou-se pelos encontros musicais. Buscou-se observar o comportamento na prática da atividade para entender de que forma se constroem os significados do lazer no contexto das relações sociais e de amizade que se formam no decorrer dessas experiências. Esses aspectos surgem como importantes pontos de análise porque contribuem para compreender a experiência vivida pelos consumidores e as construções simbólicas por eles produzidas em decorrência da prática do lazer.

$\mathrm{O}$ estudo utilizou métodos oriundos da etnografia urbana, em particular a observação participante e as entrevistas em profundidade, que vêm sendo crescentemente utilizados na disciplina de marketing e se mostraram adequados para atender à natureza do fenômeno investigado, o lazer de idosos em grupo. A escolha metodológica considerou a natureza dos estudos relacionados ao lazer, em que o ambiente, as relações, as atividades diretas ou indiretas, o espaço de interação e, sobretudo, os aspectos simbólicos são importantes para o entendimento da questão de pesquisa.

$\mathrm{O}$ ambiente de pesquisa deve proporcionar acesso ao fenômeno que se deseja investigar de modo a ter algum nível de participação, em maior ou menor intensidade, para vivenciar o fenômeno que se deseja conhecer e interpretar (Jodelet, 1989). Entretanto, ao realizar a observação participante o pesquisador deve saber separar o fenômeno do ambiente, não perdendo de vista que o espaço de observação não é o objeto de pesquisa, mas sim onde o fenômeno de investigação se manifesta (Geertz, 1973).

Inicialmente, em conversas com informantes idosos foram identificadas várias atividades de lazer em grupo e escolhido, para a realização do trabalho de campo, um grupo de encontros musicais que se reúne no Palácio do Catete, no Rio de Janeiro. A observação participante no grupo de encontro musical de seresta ocorreu no período de março de 2013 a outubro de 2013.

A opção por realizar uma pesquisa de inspiração etnográfica possibilitou utilizar diferentes técnicas de coleta de dados, típicas da etnografia, tais como observações, entrevistas informais ou casuais, gravações, fotografias, além de entrevistas em profundidade formais (Elliott \& Jankel-Elliott, 2003; Holbrook, 2006). Os dados coletados no decorrer da observação participante, à exceção das entrevistas formais (que foram gravadas e posteriormente transcritas), foram registrados em um diário de campo. Os registros em diário, gravação e fotografia foram 
feitos sistematicamente a fim de preservar a memória do que ocorreu durante o trabalho de campo. Incluíram-se aí a estrutura em que se desenrolavam as atividades de lazer, o desenvolvimento dessas atividades, o comportamento dos praticantes do lazer de Terceira Idade, a composição do lugar, os indivíduos que transitavam no espaço, as conversas casuais e as entrevistas informais. As fotografias contribuíram para remontar o cenário da observação participante posteriormente e serviram de constante fonte de inspiração no decorrer da análise.

$\mathrm{Na}$ primeira fase do trabalho de campo, procurou-se obter uma visão mais ampla do fenômeno, assumindo uma postura exploratória. Entrevistas informais foram realizadas à medida que surgiam oportunidades, não seguindo roteiro estruturado, mas apenas uma lista de temas. Já as entrevistas em profundidade, realizadas ao final da observação participante, utilizaram um roteiro desenvolvido a partir de fatores identificados na literatura consultada e da etapa inicial da própria observação participante. Durante a condução da entrevista, foram incluídas novas perguntas para explorar questões trazidas pelos próprios entrevistados, aprofundando aspectos do fenômeno que ainda não tinham sido vislumbrados nas entrevistas anteriores. As respostas a perguntas abertas se mostraram altamente reveladoras, trazendo à tona perspectivas individuais dos diversos atores envolvidos no mesmo fenômeno investigado (Cotte \& Kistruck, 2006). A seleção de entrevistados obedeceu aos seguintes critérios: (i) 60 anos ou mais; (ii) frequência regular aos encontros musicais (frequentadores assíduos, frequentadores que compareciam à seresta pelo menos uma vez ao mês, ou mesmo frequentadores contínuos em determinadas épocas do ano, como verão e primavera); (iii) participação nos encontros há pelo menos seis meses. No total, as 16 entrevistas contabilizaram mais de 20 horas de áudio, convertidas em 440 páginas de texto transcrito. Cada entrevista foi lida pelo menos três vezes; contudo muitos trechos foram revistos várias vezes.
A análise de dados seguiu a técnica da análise do discurso. A análise fundou-se em etapas que foram se processando gradativamente ao longo do trabalho de campo: (1) desenvolvimento de um conjunto de categorias e temas iniciais; (2) identificação nos diários de campo e nas transcrições de entrevistas de partes descritas no discurso dos informantes correspondentes àquelas categorias; (3) identificação de novas categorias e temas que emergiram do campo; (4) reagrupamento de categorias e temas; (5) nova leitura do diário de campo e das transcrições, incluindo retornos constantes à teoria para cotejar com o resultado das categorias e temas reagrupados; (6) seleção de novos trechos dos discursos dos informantes correspondentes às novas categorias; (7) nova consulta à teoria conforme emergiram categorias e temas que não tinham sido contemplados inicialmente.

Uma vez definidas as categorias, foi feita uma releitura de cada entrevista, seguindo a lógica "crosscase analysis" (Kohlbacher, 2006; Yin, 2005), técnica de análise que considera cada entrevista como um caso. A análise comparativa e sistemática permitiu identificar padrões de fenômenos singulares relativos ao fenômeno maior de lazer investigado, fazendo emergir assim as categorias de análise identificadas nesta pesquisa.

\section{OS ENCONTROS MUSICAIS DO PALÁCIO DO CATETE}

Os encontros musicais de seresta reúnem pessoas, há mais de 20 anos, para ouvir, tocar e cantar músicas antigas no Palácio do Catete, antiga sede da Presidência da República do Brasil. Os encontros se originaram de uma iniciativa do seresteiro Vivaldo, mais conhecido pelos frequentadores como "Vivi da Seresta". O encontro ocorre nos domingos à tarde. O Palácio do Catete abriga um grande parque em seu espaço interno, com uma vasta área verde, conhecida como Jardim do Palácio (Figura 1).

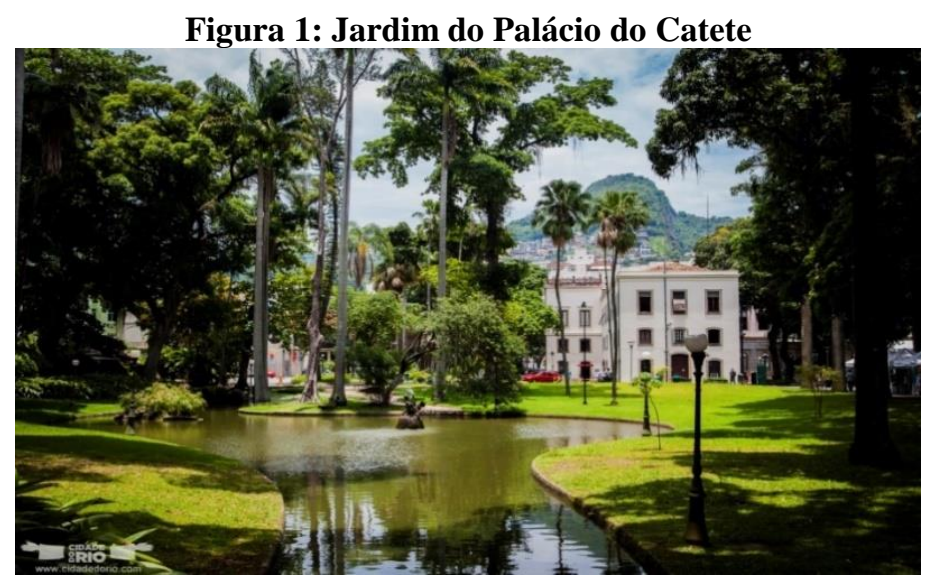


Fonte: Disponível em <http://cidadedorio.com/>. Cidade do Rio. Acesso em 07/02/2015.

O cenário em que se dão os encontros musicais de seresta - o Jardim do Palácio - é parte integrante do espetáculo, tanto para os que participam regularmente dos encontros como para espectadores ocasionais. Simultaneamente atores e plateia, os participantes comungam o prazer da música em um espaço aberto. $\mathrm{O}$ espaço é aberto diariamente para visitação pública. A Seresta do Vivi ocorre no meio do parque, em um espaço próximo ao chafariz, onde há bancos para os frequentadores apreciarem o jardim. Nos dias de seresta, a administração do parque fornece cadeiras adicionais aos frequentadores.

Os frequentadores mais assíduos são idosos. Para o seresteiro Vivi, "a Terceira Idade é a cara da seresta". Ele acredita que os idosos apreciam as músicas antigas porque trazem recordações de pessoas e momentos de sua vida. Também os que cantam nos grupos são, em sua maioria, idosos. Os idosos participam de formas distintas dos grupos de seresta. Alguns vão para cantar, outros apenas para ouvir e desfrutar o momento, apreciando o ritmo, o estilo musical e a música ao vivo. Outros, além de ouvir, acompanham as músicas formando um coro. Alguns chegam a dançar durante as apresentações musicais da seresta. Entre os idosos há também cadeirantes.

No entanto, os grupos de seresta não reúnem somente idosos, muito embora seja esse o segmento etário majoritariamente presente nas apresentações, dado que todos os que cantam e tocam instrumentos são idosos. Entre aqueles que participam ouvindo e contribuindo para o coro durante as apresentações, há variações quanto à faixa etária. Porém, os mais jovens tendem a ser participantes ocasionais, que param para ouvir e, geralmente, participam apenas uma vez ou outra. A Figura 2 mostra duas apresentações do Vivi acompanhando senhoras que cantavam.

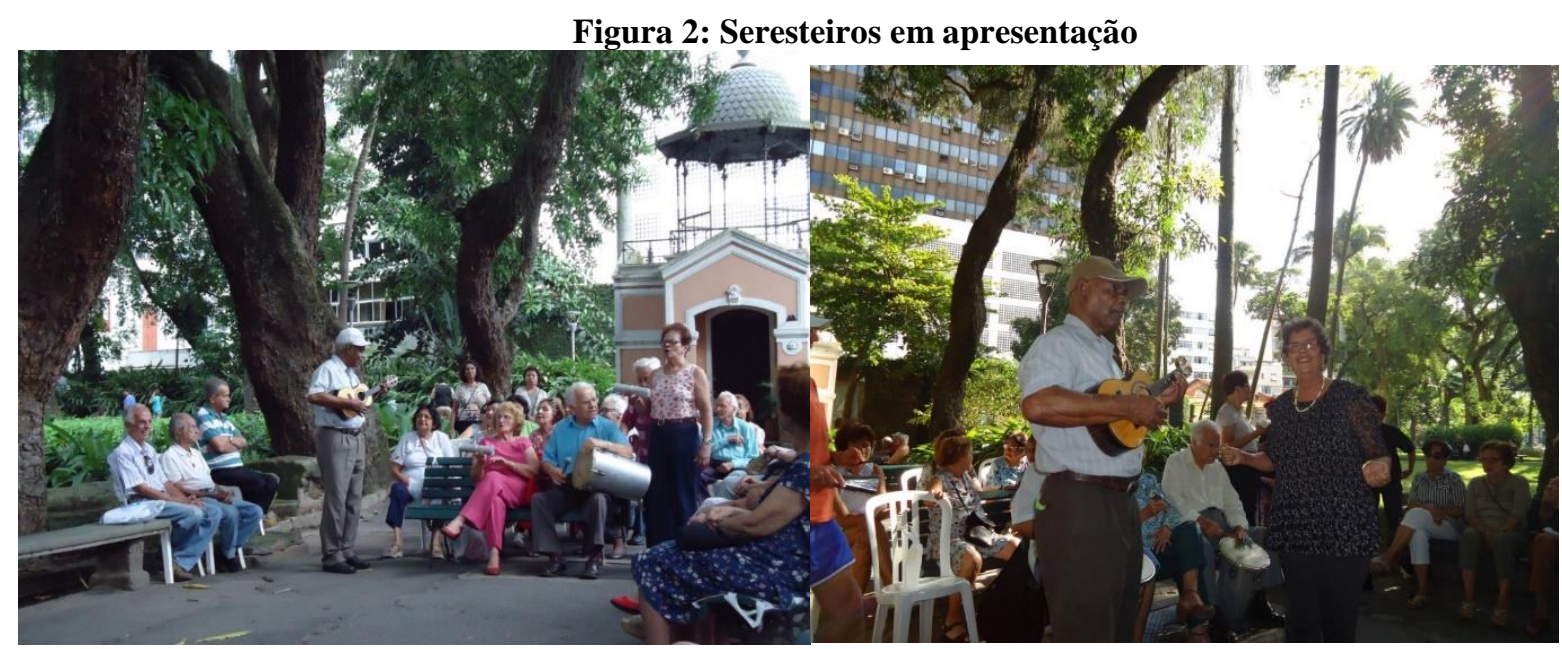

Fonte: Acervo da Pesquisa.

Vivi chegou ao Rio de Janeiro em 1991 e tentou "ganhar a vida" com a música. Começou a tocar cavaquinho naquele mesmo ano, aos domingos, nos jardins do Palácio do Catete, atraindo a atenção de transeuntes. Com o tempo o público foi aumentando e alguns frequentadores se tornaram assíduos. Nascia assim o encontro musical a que Vivi deu o nome de Seresta. Vivi exerce diferentes papéis no grupo, como animador, cantor e instrumentista. Para ele, a seresta tem um caráter construtivo para os idosos que a frequentam, por terem a oportunidade de aprender alguma coisa, dentro de seu próprio interesse. Alguns "criam coragem" e aprendem a cantar. Outros aprendem a "mexer em instrumentos", enquanto outros ainda aprendem a gostar de novos gêneros musicais.

Foram entrevistados, além do seresteiro Vivi, quinze idosos frequentadores do Grupo de Seresta do
Palácio do Catete, sendo sete homens e oito mulheres. O Quadro 1 apresenta dados demográficos dos entrevistados. Com exceção do seresteiro Vivi, figura pública, todos os demais entrevistados tiveram seus nomes disfarçados. $\mathrm{O}$ perfil econômico varia substancialmente. À luz da classificação socioeconômica do Critério Brasil da Associação Brasileira de Empresas de pesquisa [ABEP] (2013), alguns entrevistados são de classe média-alta, pertencendo aos estratos B1 e B2, enquanto outros são classificados como de classe média baixa, pertencendo aos estratos $\mathrm{C} 1$ e $\mathrm{C} 2$. Dois entrevistados não pertencem à classe média, sendo um deles pertencente à classe $\mathrm{D}$, e outro pertencente à classe A. Alguns participantes não informaram a renda. 
Quadro 1: Perfil dos Entrevistados

\begin{tabular}{|c|c|c|c|c|c|c|}
\hline Entrevistado & $\begin{array}{l}\text { Ida- } \\
\text { de }\end{array}$ & Sexo & Formação & Ocupação & Mora com & Renda \\
\hline Alice & 70 & $\mathrm{~F}$ & Graduação & $\begin{array}{l}\text { Designer } \\
\text { aposentada }\end{array}$ & Mora sozinha & $\mathrm{R} \$ 1.900$ \\
\hline Almerinda & 77 & $\mathrm{~F}$ & Ensino Médio & $\begin{array}{l}\text { Funcionária } \\
\text { pública } \\
\text { aposentada }\end{array}$ & Mora sozinha & $\mathrm{R} \$ 4.100$ \\
\hline Artur & 72 & M & Ensino Médio & $\begin{array}{l}\text { Garçom } \\
\text { aposentado }\end{array}$ & Mora sozinho & $\mathrm{R} \$ 724$ \\
\hline Donato & 60 & M & Ensino Médio & Agropecuarista & $\begin{array}{l}\text { Mora } \quad \text { com } \\
\text { esposa }\end{array}$ & $\begin{array}{r}\text { Não } \\
\text { informou }\end{array}$ \\
\hline Elaine & 67 & $\mathrm{~F}$ & Graduação & $\begin{array}{l}\text { Aposentada e } \\
\text { promotora de } \\
\text { viagens }\end{array}$ & $\begin{array}{l}\text { Mora } \quad \text { com } \\
\text { irmão }\end{array}$ & $\mathrm{R} \$ 5.000$ \\
\hline Elizinha & 68 & $\mathrm{~F}$ & $\begin{array}{l}\text { Ensino } \\
\text { Fundamental }\end{array}$ & Pensionista & Mora sozinha & $\mathrm{R} \$ 1.800$ \\
\hline Gisela & 71 & $\mathrm{~F}$ & Ensino Médio & Pensionista & Mora com filha & $\mathrm{R} \$ 3.000$ \\
\hline Jorge & 60 & $\mathrm{M}$ & Ensino Médio & Motorista/DJ & Mora com irmã & $\mathrm{R} \$ 1.500$ \\
\hline Justina & 81 & $\mathrm{~F}$ & Graduação & $\begin{array}{l}\text { Advogada } \\
\text { aposentada }\end{array}$ & Mora sozinha & $\begin{array}{r}\text { Não } \\
\text { informou }\end{array}$ \\
\hline Leo & 77 & $\mathrm{M}$ & Graduação & $\begin{array}{l}\text { Médico } \\
\text { aposentado }\end{array}$ & Mora sozinho & U\$ 14.500 \\
\hline Luciano & 75 & M & Ensino Médio & $\begin{array}{l}\text { Radialista } \\
\text { aposentado }\end{array}$ & $\begin{array}{l}\text { Mora } \quad \text { com } \\
\text { esposa }\end{array}$ & $\mathrm{R} \$ 2.000$ \\
\hline Mario & 79 & M & $\begin{array}{l}\text { Ensino } \\
\text { Fundamental }\end{array}$ & $\begin{array}{l}\text { Mecânico } \\
\text { aposentado }\end{array}$ & Mora sozinho & $\mathrm{R} \$ 1.500$ \\
\hline Marta & 68 & $\mathrm{~F}$ & Ensino Médio & $\begin{array}{l}\text { Professora } \\
\text { aposentada/ } \\
\text { balconista }\end{array}$ & Mora sozinha & $\mathrm{R} \$ 2.500$ \\
\hline Matilde & 83 & $\mathrm{~F}$ & Ensino Médio & $\begin{array}{l}\text { Costureira } \\
\text { aposentada }\end{array}$ & Mora sozinha & $\mathrm{R} \$ 1.850$ \\
\hline Vivi & 81 & M & $\begin{array}{l}\text { Ensino } \\
\text { Fundamental }\end{array}$ & $\begin{array}{l}\text { Aposentado/ } \\
\text { músico }\end{array}$ & Mora sozinho & $\begin{array}{r}\text { Não } \\
\text { informou }\end{array}$ \\
\hline Walter & 66 & M & Ensino Médio & $\begin{array}{l}\text { Auxiliar } \\
\text { Administrativo }\end{array}$ & $\begin{array}{ll}\text { Mora } & \text { com } \\
\text { esposa }\end{array}$ & $\mathrm{R} \$ 3.500$ \\
\hline
\end{tabular}

Fonte: Elaborado pelos autores.

\section{SIGNIFICADOS DA PRÁTICA DE LAZER NO GRUPO DE SERESTA}

Esta seção apresenta e discute os significados atribuídos à prática do lazer no Grupo de Seresta do Palácio do Catete. Seis diferentes categorias emergiram do trabalho de campo: (1) significado hedônico; (2) espaço de sociabilidade; (3) nostalgia; (4) qualidade de vida; (5) (re)construção da identidade; e (6) aprendizado. Essas categorias são detalhadas e analisadas a seguir. As seis categorias finais e os significados associados são apresentados no Quadro 2. 


\section{Quadro 2: Categorias: Descrição, Significados e Principais Termos e Expressões Associados - Grupo de Seresta}

\begin{tabular}{|c|c|c|}
\hline Categoria & escrição da categoria & gnificados e Principais Termos e Expressões Associados \\
\hline $\begin{array}{l}\text { Significado } \\
\text { Hedônico }\end{array}$ & $\begin{array}{l}\text { Utiliza o conceito de } \\
\text { Holbrook e Hirschmann } \\
\text { (1982), englobando duas das } \\
\text { três dimensões sugeridas por } \\
\text { esses autores: sentimentos } \\
\text { (feelings) e diversão (fun). }\end{array}$ & 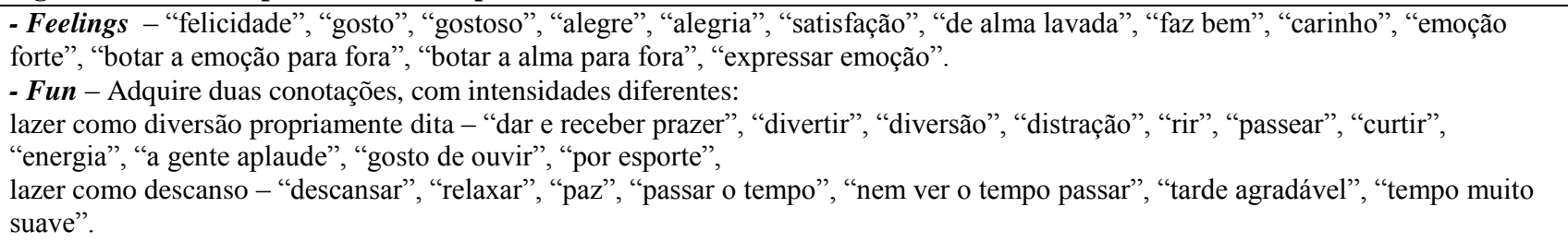 \\
\hline dade & $\begin{array}{l}\text { entre idosos, pro } \\
\text { amizades, interaç } \\
\text { suporte mútuo. }\end{array}$ & 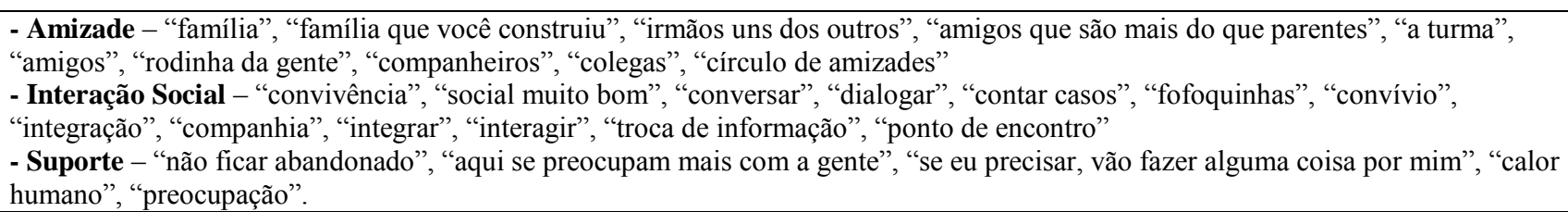 \\
\hline Nos & $\begin{array}{l}\text { ciados } \\
\text { tigas. }\end{array}$ & $\begin{array}{l}\text { - Retorno ao Passado - "volta ao passado", "lembrar as coisas boas", "lembrar entes passados", "quando o primeiro beijo, primeira } \\
\text { sacanagem, primeiro tudo..."; "amor relembrado", "uma passagem na sua vida". } \\
\text { - Recordação das músicas - "recordar canções", "lembrar músicas antigas", "música daqueles tempos", "resgatar canções antigas", } \\
\text { "reviver canções de amor", "música de dor de cotovelo", "canções de artistas que já se foram”. }\end{array}$ \\
\hline $\begin{array}{l}\text { Qua } \\
\text { de V }\end{array}$ & s pela & 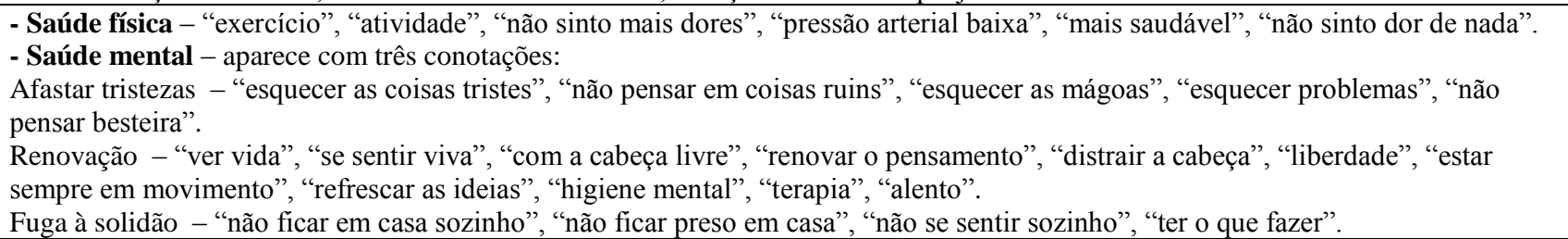 \\
\hline $\begin{array}{l}\text { (Re) } \\
\text { Construção da } \\
\text { Identidade }\end{array}$ & $\begin{array}{l}\text { Consiste em se reinventar } \\
\text { como pessoa, por meio da } \\
\text { descoberta do novo e de } \\
\text { superação do passado; de } \\
\text { reforço à autoestima; e de } \\
\text { renovado cuidado de si. }\end{array}$ & $\begin{array}{l}\text { - Descoberta - "dádiva", "presente", "descoberta da vida", "uma parte de mim que estava guardada" } \\
\text { - Superação - "voltar a cantar", "vencer trauma", "ninguém me segura", "bater asas, voar", "desenvolver", "crescer", "tornar-se uma } \\
\text { pessoa completa", "realizar projeto pessoal", "fazer bem a si mesmo". } \\
\text { - Autoestima - "ser requisitada", "agradar [aos outros]", "massagear o ego", “passar confiabilidade", "influenciar", "ser } \\
\text { reconhecido", "ser aplaudido", "aplauso para o ego", "bom para o psicológico". } \\
\text { - Cuidado de si mesmo - "produzir-se", "cuidar de si", "arrumar-se", "ajeitar-se". }\end{array}$ \\
\hline Aprendizado & $\begin{array}{l}\text { Inclui o aprendizado musical } \\
\text { e o aprendizado social (lidar } \\
\text { com a diversidade, } \\
\text { principalmente de classe) e o } \\
\text { aprendizado prático. }\end{array}$ & $\begin{array}{l}\text { - Aprendizado Musical - "aprender a tocar", "aumentar o repertório", "aprender mais músicas", "aprender mais letras", "descobrir o } \\
\text { balanço da música", "entrar no tom certo", "acertar o arranjo", "cantar melhor". } \\
\text { - Aprendizado Social - "não tem diferença", "somos todos iguais", "movimento de amor, de carinho com os outros", "saber lidar } \\
\text { com cada pessoa", "aprender a respeitar as pessoas, a não fazer prejulgamento". } \\
\text { - Aprendizado Prático - "dar uma ideia para o outro", "ouvir outras ideias", "passar mensagem", "aprender sobre a vida", "dar } \\
\text { dicas", "trocar experiências". }\end{array}$ \\
\hline
\end{tabular}

Fonte: Elaborado pelos autores.

" prendizado Prático - "dar uma ideia para o outro" "ouvir outras ideias" "passar mensagem", "aprender sobre a vida", "dar 
Como se observa no Quadro 2, as categorias de análise emergiram dos dados colhidos no discurso dos informantes. A partir dos principais termos presentes nesse discurso, assim como expressões associadas à atividade de lazer e à significação atribuída ao lazer, foi possível realizar a análise sistemática dos dados, chegando-se às categorias identificadas. Para ser fiel ao conteúdo identificado, as falas dos entrevistados são mantidas conforme originalmente recolhidas. Da mesma forma, as passagens apresentadas nas discussões das categorias a seguir mantêm essa estrutura, preservando, inclusive, as expressões cotidianas informais mencionadas pelos informantes.

É interessante observar também que os variados contextos em que se inserem os idosos influem para que se manifestem diferentes significados com relação ao lazer. Coupland, Coupland e Giles (1991) verificaram essa fragmentação nos interesses dos idosos, de tal modo que suas identidades sofreriam variações com o tempo e o contexto, refletindo as circunstâncias locais em que tais identidades foram construídas e a realidade em que se encontram inseridas.

\section{- Significado Hedônico}

Os encontros musicais são, essencialmente, uma atividade hedônica. No entanto, o significado hedônico remete não só à música em si, mas a outros aspectos dos encontros musicais. Pode ser analisado sob a perspectiva da diversão em si (indicado como "diversão", “distração", "passeio", "curtição" e também como "relaxamento" e "descanso") e dos sentimentos (tais como "felicidade", "alegria", "satisfação", "carinho" e "beleza"). Jorge observa: "As músicas são importantes na minha vida... A música desperta sentimentos. Aprofunda sua sensibilidade. Desperta uma empolgação danada". E Donato explica: "Para mim, é uma coisa que traz tanta alegria, paz, coisas simples, nada complicado, todo mundo canta do jeito que canta, não importa como...”. E Matilde: "A música é a beleza da vida. A minha felicidade é a música. O grupo me traz alegria, eu me sinto viva... Eu vivo aquilo... Eu sou apaixonada por música porque ela me modifica... Me faz melhor. [...]. Então aquilo sacia, eu saio assim liberta, livre". A experiência proporcionada pela participação no grupo de encontro musical do Palácio do Catete possui um apelo hedônico, conforme se pode depreender das falas dos idosos entrevistados. Diversão e sentimentos são, na verdade, duas das categorias já identificadas no estudo de Holbrook e Hirschman (1982) no consumo hedônico, por eles chamadas de fun e feelings. A terceira categoria que os autores encontram na manifestação hedônica, fantasies, não foi identificada nesta pesquisa. As falas dos entrevistados mostram ainda que a motivação hedônica remete ao desejo pelo consumo a partir da experiência proporcionada pelo contato com o objeto de consumo (Brakus, Schmitt \& Zarantonello, 2009). Assim, a participação no encontro musical leva à aquisição de CDs dos seresteiros e ao consumo das músicas por outros meios (compra de $\mathrm{CD}$ dos cantores originais em loja, rádio, internet etc.), além do interesse por ter aulas de canto, comprar e aprender a tocar instrumentos, definindo hábitos ou reorientando preferências.

Holbrook e Hirschman (1982) ensinam que o apelo simbólico motiva os indivíduos para o consumo de algo em razão do impacto que a experiência promove nos sentidos e nas emoções, sendo essa a motivação hedônica do consumo. Pode incluir várias atividades lúdicas, prazeres sensoriais, devaneios, prazer estético e respostas emocionais que promovam a motivação hedônica, que acontece não pela atividade em si, mas pelo valor e significado para seus participantes. De acordo com Guido, Capestro e Peluso (2007), a experiência hedônica ocorre quando o objeto de consumo tem um valor que vai além de seus atributos utilitários, incluindo também os atributos emocionais e multissensoriais. No caso do grupo de Seresta, conforme se observa no discurso dos entrevistados, o encontro musical ultrapassa o simples ato de apreciar uma boa música, seja cantando, ouvindo ou dividindo o momento com outros participantes da Seresta, despertando sentimentos por eles descritos.

Os depoimentos dos frequentadores da Seresta relativos à experiência de participar do grupo de encontro musical evidenciam o caráter hedônico do consumo de suas atividades e produtos ali oferecidos, como o CD dos Seresteiros. Ainda que indiretamente, o grupo de Seresta proporciona experiências em seu ambiente (Araujo e Chauvel, 2012; Pine II e Gilmore, 1998), seja oferecendo música aos ouvintes, seja incentivando ou abrindo espaço para as pessoas cantarem, seja favorecendo às pessoas a se conhecerem e interagirem. Para Schmitt (2001), essas associações afetivas podem resultar em experiências que mexem com suas emoções, gerando estímulos cognitivos em relação ao grupo de encontro musical e aos benefícios que o grupo oferece. Esses benefícios, segundo Brakus, Schmitt e Zarantonello (2009), podem representar experiências capazes de influenciar positivamente a decisão de retorno continuado dos frequentadores do grupo de encontro musical.

\section{- Espaço de Sociabilidade}

O Grupo de Seresta é, sobretudo, um espaço de sociabilidade para os idosos. Os 
entrevistados convergiram em ressaltar a importância do encontro musical para construção de relacionamentos. Alguns sublinharam, inclusive, que sua motivação para participar era encontrar um espaço onde pudessem interagir com pessoas que se interessassem em conhecer novas pessoas e fazer amizades. No entanto, a profundidade e a extensão desses relacionamentos podem variar de "conhecidos" (Justina) a "irmãos" (Walter) e "família" (Alice, Elaine). Gisela explica: "A gente faz uma porção de amizades aqui, eu gosto muito de conversar. [...] Porque você tem uma companhia ali, com quem conversar, com quem dialogar... Assim, amigos, companheiros...". Entre os entrevistados, apenas Donato não se vê como parte do grupo, mas como um estranho, definindo-se como um "outsider".

A experiência desses consumidores remete a fenômenos já estudados por pesquisadores de marketing e de comportamento do consumidor, como a influência do grupo social. Segundo Ward e Reingen (1990), algumas atividades de consumo advêm da experiência compartilhada por grupos de amigos e, nesse sentido, a experiência de cantar e ouvir música revela diferentes influências no comportamento de consumo dos idosos entrevistados. A começar pelo consumo da própria atividade, em que a interação entre as pessoas de Terceira Idade que frequentam o local contribui para sua atração e permanência. Muitos deles incentivam uns aos outros a contribuírem com a "caixinha" dos músicos. Além disso, alguns elaboraram CDs amadores que são consumidos por muitos frequentadores.

Para alguns, tais como Almerinda, Elaine e Justina, os elos de amizade estabelecidos com outros são o elemento principal da experiência vivida no grupo. Tais vínculos envolvem ainda a certeza de que alguém "se preocupa", "se importa" com a pessoa, pessoas "que sentem falta", "mais que, às vezes, a família". Porque se está falando, para alguns, de uma outra família, "aquela família que você não herdou, aquela que você construiu", que pode ser "a mais importante". As relações sociais que se estabelecem no encontro musical geram novos encontros: festas, aniversários, outros eventos musicais, happy hours em barzinhos, restaurantes ou na casa de alguém, solidificando os laços entre os participantes. Os passeios e as viagens em grupo são outras formas de consumo indiretamente promovidos pelas interações sociais que emergiram entre os frequentadores da Seresta. Assim, o discurso dos entrevistados informa que a realização de atividades em grupo, que promovem interação, construção de amizades e troca de experiências, pode se revelar ambiente propício para o fomento de atividades de consumo.

\section{- Nostalgia}

A nostalgia surge no discurso dos entrevistados de duas formas. De um lado, quando destacam que a participação no encontro musical permite, por meio da música, reviver bons momentos guardados na memória, lembrar-se de pessoas queridas, ou de ocasiões especiais vividas no passado. De outro, quando valorizam ouvir e resgatar músicas antigas, do passado, que apreciavam e de que, por vezes, já perderam em parte a lembrança. Esse resgaste de lembranças do passado permite despertar sentimentos relacionados à experiência anterior. Alguns pesquisadores acreditam que as pessoas podem ser mais nostálgicas durante os períodos de transição da vida (Havlena \& Holak, 1991). À medida que envelhecem, os indivíduos se tornam mais suscetíveis ao sentimento de nostalgia e, dessa forma, ficam abertos a experiências que nutram esse sentimento. Assim, os consumidores idosos se valem da experiência do passado para reviver sentimentos e emoções positivos.

Holbrook e Schindler complementam esse debate ao colocar que o sentimento de nostalgia ajuda a compreender as preferências em relação a objetos, lugares ou coisas que eram comuns em algum momento anterior da vida do indivíduo. Em outro estudo, Schindler e Holbrook (2003) relacionam as experiências vividas com o desenvolvimento de gostos e preferências, tais como gosto musical, aparência pessoal, produtos culturais etc. Os autores defendem que tais experiências tendem a influenciar o comportamento do consumidor em outras fases da vida.

A nostalgia pode se apresentar de duas formas, individual e coletiva (Havlena \& Holak, 1991). A nostalgia individual está relacionada aos eventos pessoais ou às experiências passadas da vida privada. A nostalgia coletiva está relacionada a sentimentos de alegria, prazer e segurança que emanam de imagens de eventos históricos, ou tempos partilhados com outros. No presente estudo foram identificadas as duas formas. Por exemplo, Alice e Jorge, possivelmente em função de seus interesses como músicos amadores, valorizam o resgate das canções do passado sob uma perspectiva individual. Já Almerinda, Artur, Leo e Mario percebem um resgate conjunto do passado e Luciano atribui uma conotação de resgate político da música de sua geração.

Os depoimentos sugerem que os idosos encontram sentimentos positivos a partir das músicas antigas que revivem ligações com pessoas ou momentos especiais de suas vidas, e que compartilham esses sentimentos com outros idosos, resgatando a emoção da lembrança e o prazer experimentado no passado. A nostalgia possibilita o 
reforço de suas identidades a partir da memória e da manutenção de fatos positivos que os indivíduos reconhecem como "seus", isto é, fatos que dão sentido a sua existência (Havlena \& Holak, 1991).

\section{- Qualidade de Vida}

A categoria "Qualidade de Vida" engloba significados positivos e negativos, que foram agrupados em duas grandes dimensões, correspondendo à saúde física e mental. $\mathrm{O}$ primeiro eixo de significados é quase objetivo, ao englobar as questões relativas a exercício e atividade, pois, embora não haja atividade física específica associada ao encontro musical, sua localização no parque permite que se faça uma caminhada, o que é registrado por alguns. Além disso, associam-se alguns benefícios físicos à atividade, que emanam, possivelmente, do bem-estar psicológico (tais como "não sentir mais dores no corpo", ou mesmo baixar a pressão arterial).

Um segundo eixo de significados dentro dessa categoria se refere à saúde mental, ao bemestar, a "viver mais" (Walter), ou, simplesmente, a "viver": "você não está morto, está vivendo" (Gisela). São inúmeras as menções, nas falas dos entrevistados, a aspectos relacionados à saúde. Por exemplo, Luciano considera que "contribui muito para a mente dos idosos"; Marta fala de "higiene mental" e Matilde vê como "terapia". Dentro da saúde mental, aparecem os sentimentos e sensações positivos oriundos de maior qualidade de vida: tranquilidade, novo ânimo, relaxamento, fortalecimento, estímulo, alento, enriquecimento e paz interior, porque "a música lava a alma da gente" (Marta), traz "outra mentalidade" (Artur). Provonost (2011) aponta que a decisão do consumo de lazer inclui o investimento na saúde psíquica e mental, proporcionando momentos de prazer e alegria, e possibilitando evadir-se das dificuldades e dos sofrimentos da vida.

Por fim, há a fuga de sentimentos negativos (tristeza, depressão e solidão), de "pensamentos ruins" (Artur), de "mágoas" (Matilde), de "problemas da vida" (Walter). É preciso fugir desses sentimentos, pensamentos e realidades, e a melhor forma de fazer isso é sair de casa, buscar a convivência com outras pessoas da mesma idade, que têm coisas em comum em sua experiência de vida. Na opinião dos entrevistados, o Grupo de Seresta permite superar essas dificuldades, tornando-se um abrigo, um consolo, uma distração. Segundo Gergen e Gergen (2000), os idosos buscam na interação social uma forma de afastar-se dos problemas pessoais. Venkatesh (2006) também sugere que o lazer pode servir como importante escape para a vida mundana.

\section{- (Re)Construção da identidade}

A questão da reconstrução de identidade se manifestou no discurso dos entrevistados por meio da descoberta do novo e pela superação de barreiras, levando a autorrealização e fortalecimento da autoestima e do ego, e a renovado cuidado de si mesmo.

$\mathrm{Na}$ categoria "(re)construção da identidade" há casos marcantes, como os de Alice, Elaine, Elizinha e Marta, além do próprio Vivi, fundador do grupo. Esses entrevistados revelaram que a Seresta promoveu um encontro mais profundo consigo mesmos, propiciando, já em idade avançada, uma oportunidade de realização pessoal, que trouxe novo significado a suas vidas. Alice sempre desejou cantar, mas foi cerceada pela família, que não considerava que isso fosse adequado a "moça de família". Depois de 50 anos longe da música, ela encontrou o Grupo de Seresta, para ela "uma dádiva". No começo "cantava baixinho", mas foi-se libertando dos traumas e acabou por se apresentar em público. O sucesso nas apresentações fez com que passasse a se cuidar mais, reforçando sua autoestima. Elizinha, mais do que qualquer outro entrevistado, é quem melhor representa a categoria "(re)construção da identidade". Ao se tornar cantora amadora, a partir da experiência com o Grupo de Seresta, mas já com incursões profissionais, ela teve "a grande descoberta" de sua vida: "Agora eu vivo realmente. Antes, eu vivia a vida para os outros...". Também Marta, que sempre desejou ser cantora, encontrou no grupo o estímulo necessário, chegando a se apresentar em festivais e a gravar um CD amador. Principalmente para Elizinha e Marta, a experiência levou a uma reestruturação identitária, em que a música, assim como as atividades relacionadas, serviu de principal motivador para o encontro com um novo "eu". Já para Elaine, o grupo gerou a oportunidade de se dedicar profissionalmente à atividade de turismo, organizando excursões de idosos. Crê que passa "confiabilidade" e tem "espírito de liderança", o que faz com que seu trabalho seja "considerado" e "reconhecido". Em função disso, sente-se "aceita" e "querida". Como salientou Bauman (2005), as identidades não são fixas, mas fluidas, e se modificam no tempo e no espaço. Holt (2002), por sua vez, pontua que a estruturação de uma identidade passa pela criação de significados atribuídos a coisas e atividades com que o indivíduo se identifica, que são úteis para transmitir seus valores e referenciá-los em seu contexto social.

Marta menciona que o movimento da Seresta a encorajou a aprofundar sua relação com a música e com a voz. Como desejava ser cantora, mas se tornou professora, foi no grupo de encontro 
musical que voltou à prática do canto. A partir da Seresta, ela se apresentou em festivais de música e gravou um CD amador. Firat e Venkatesh (1995) salientam que a identidade do indivíduo passa pela forma como este se vê e, nesse contexto, a autoidentificação como cantora está presente na identidade construída por Marta.

Para outros entrevistados, a participação no Grupo de Seresta também significou autonomia e reforço da autoestima, embora de formas distintas. A participação no grupo é recorrentemente descrita como um momento pessoal, escolhido pelo próprio entrevistado. Em alguns casos, o discurso revela o viés libertador que a escolha dessa atividade de lazer traz para o participante. Por exemplo, Almerinda ressalta que se vê "livre" e "independente". Para Luciano, a possibilidade de escolha é o motor para que prossiga: "Escolho o que eu quero fazer, tenho o que fazer aqui e isso me estimula a estar sempre em movimento". Como colocam Barnhart e Peñaloza (2013), quando o idoso realiza com sucesso uma atividade de consumo desejada, reafirma sua capacidade física e cognitiva diante de si e dos outros, significando autonomia e valorização do "eu".

\section{- Aprendizado}

A última categoria identificada, entre os significados atribuídos pelos idosos ao encontro musical, foi a oportunidade de aprendizado. Estudos recentes também sugerem que os consumidores de Terceira Idade podem buscar atividades novas nessa fase da vida que levam a aprendizado (por exemplo, Myers \& Lumbers, 2008). Para Searle et al. (1998), o lazer proporciona ao idoso senso de independência e bem-estar psicológico. Alguns entrevistados destacam que a participação no grupo de seresta abriu caminho para o aprendizado musical. Foi o que ocorreu com Matilde e Walter, em quem a seresta despertou o desejo de aprender mais sobre música. Matilde se sentiu naturalmente inspirada a ter aulas de canto, enquanto Walter comprou um violão e deseja aprender a tocar o instrumento. Por sua vez, a seresta despertou em Jorge o desejo de aprender mais sobre músicas antigas, levando-o a pesquisar na internet. Gergen e Gergen (2000) afirmam que a participação ativa de idosos em várias atividades sociais, incluindo aquelas que gerem aprendizado, caracteriza o que vem sendo chamado de "envelhecimento positivo". Cabe mencionar a experiência de Elizinha com a produção de três CDs amadores, na qual a atividade de lazer revela a expressão de uma atividade artística manifestada como forma de autorrealização (Colbert, 2012).

Há ainda o aprendizado social, que apresenta diversas facetas, desde saber lidar com a diversidade social até aprendizados práticos oriundos da troca de experiências, como nos seguintes depoimentos: "aprende-se a lidar com os diferentes tipos de pessoas" (Marta), "ajuda a saber conviver com cada um" (Justina); permite "aprender com a experiência do outro e, assim, entender o outro lado da vida" (Gisela); "aprender a respeitar as pessoas, a tratar com carinho [...]" (Alice); "aqui se aprende sobre a música e sobre a vida" (Jorge). Assim, o lazer também surge como oportunidade de aprendizado para os idosos, contribuindo para maior satisfação na vida pessoal e social.

A Figura 3 resume os significados emergentes da pesquisa. 
Figura 3: Representação Gráfica das Categorias e Significados no Grupo de Seresta

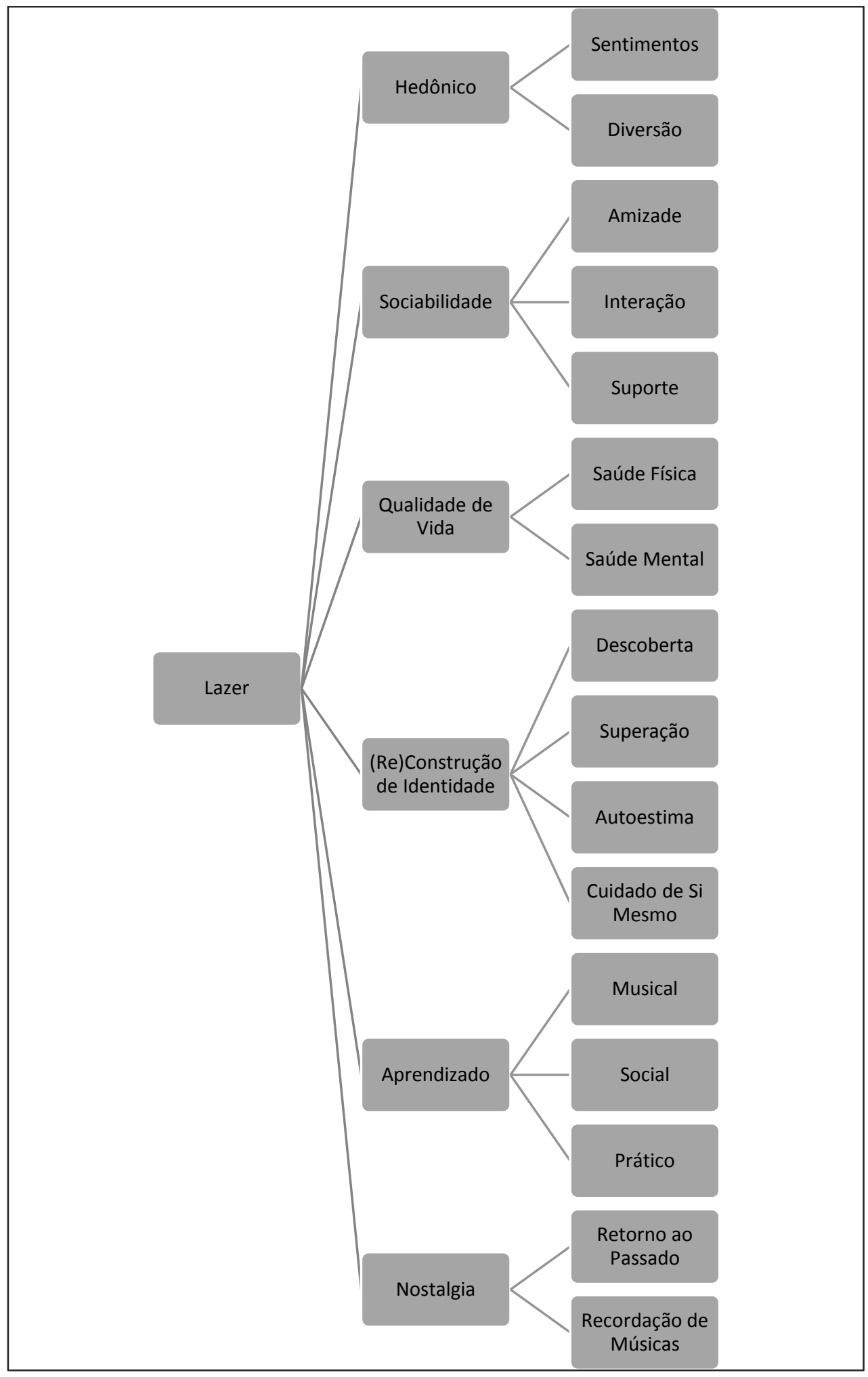

Fonte: Elaborada pelos autores. 


\section{CONSIDERAÇÕES FINAIS}

O grupo de Seresta é um grupo aberto, em que não é necessária autorização para ingresso na atividade, bastando o indivíduo ter o desejo de vivenciar a experiência do encontro musical. A participação no grupo é inicialmente demarcada pela simples frequência constante, por meio da qual se constroem ao longo do tempo as relações. Os rituais de aceitação passam pelo convite para cantar, pela participação em atividades de suporte à organização do grupo e, de forma mais marcante e definitiva, pelo convite para participar em atividades fora do local do encontro musical. A pertinência ao grupo, por fim, é consagrada pelas relações de amizade que se estabelecem. Essas características fazem com que um participante do encontro musical possa ser tanto alguém "de dentro" como alguém "de fora" (ou seja, um outsider). Trata-se, em última instância, de uma escolha mútua: tanto do indivíduo, que busca ou não a aproximação, quanto do grupo, que manifesta os sinais de que sua proximidade é ou não desejada. Os rituais de aceitação exercem uma função fundamental para os participantes de Terceira Idade, sendo vistos como símbolos de "agradar aos outros", ser "requisitado", "aplaudido" ou "reconhecido". Sem dúvida, a aceitação no grupo é vista como uma conquista pelos idosos.

Uma vez finalizado o processo de inserção plena na prática da atividade de lazer e de aceitação no grupo, o próprio significado do que é a Terceira Idade se modifica, na perspectiva do indivíduo e, em muitos casos, daqueles que o cercam. O que é mais relevante é que a ressignificação da Terceira Idade, assim produzida, é dominada por significados muito mais positivos do que negativos. A Terceira Idade pode então ser vista como libertação, ou como espaço para escolhas satisfatórias, que permitam um envelhecimento saudável e feliz. Os aspectos negativos da Terceira Idade são afastados nesse processo, rejeitando-se as ideias de solidão, afastamento e perda, e ancorando essa fase da vida em novas conquistas, novas relações e novos aprendizados. Nesse contexto, ocorre aqui, para esse conjunto de idosos, uma clara construção de um novo significado para a própria noção de Terceira Idade.

A pesquisa evidencia que as escolhas relacionadas a uma atividade de lazer reafirmam a capacidade dos consumidores idosos de construir, manter e negociar identidades, bem como assinalam mudanças importantes de atitudes, hábitos e comportamentos. O estudo contribui para melhor compreensão dos significados atribuídos por consumidores de Terceira Idade ao consumo de lazer em grupo, pois tais significados são construídos na prática do consumo e são identificados no discurso dos praticantes. Nesse sentido, a pesquisa oferece uma visão dinâmica do processo de atribuição, transferência e negociação de significados a partir das atividades de lazer. O consumidor de Terceira Idade emerge como cocriador desse processo, assumindo um posicionamento ativo na construção subjetiva de significados e na forma pela qual tais significados são usados para ressignificar a Terceira Idade.

$\mathrm{O}$ estudo traz implicações práticas principalmente para os prestadores de serviço da área de lazer. Inicialmente, cabem algumas considerações gerais que se aplicam a qualquer tipo de produto ou serviço oferecido a esse segmento. Os significados identificados no estudo refletem necessidades dos consumidores idosos, de caráter simbólico, mas nem por isso menos "reais". Dada a importância desses significados para os idosos, é importante, mesmo para empresas que não atuam no segmento de lazer, levar em conta em que medida seus produtos e serviços atendem, ou podem atender, a algumas das necessidades que se encontram atreladas a esses significados. O conhecimento proporcionado por este trabalho pode auxiliar as empresas a desenvolverem estratégias mais adequadas às expectativas e interesses do segmento de idosos, podendo contribuir para proporcionar mais satisfação com as opções de lazer por eles selecionadas. Assim, os resultados do estudo sugerem que os consumidores idosos podem ser segmentados a partir dos distintos significados atribuídos ao lazer, que parecem traduzir os benefícios buscados por esses consumidores. Assim como destacado por Vargo e Lusch (2004), o consumidor é sempre um coprodutor e seu envolvimento ajuda a ajustar as ofertas às suas necessidades. Nesse sentido, o papel do significado atribuído pelo consumidor em relação ao consumo de uma atividade de serviço, como o lazer, ganha maior importância do que a lógica da troca, fato que corrobora a importância de crenças, de valores e da cultura do consumidor diante de uma decisão de determinadas práticas de consumo.

Particularmente nesta pesquisa, os indivíduos de Terceira Idade procuram as atividades de lazer por motivos que vão além da prática específica, mas incluem questões relativas ao aprendizado de forma mais ampla, à interação social, à construção de amizades, à realização de atividades físicas e ao preenchimento do tempo com uma atividade prazerosa, entre outras. Essas mesmas necessidades podem ser preenchidas por outras atividades de lazer e não apenas por aquelas aqui estudadas. Ressalta-se também que os consumidores de Terceira Idade do encontro musical, ao aderirem à atividade, podem se tornar 
também consumidores de uma série de outros produtos musicais, inclusive CDs amadores e os mais variados instrumentos musicais. Também passam a consumir aulas de canto e de diferentes tipos de instrumentos musicais. Seu interesse se estende ainda à frequência a outros ambientes de música. Por fim, também passam a consumir outras atividades de lazer em grupo, como viagens turísticas.

Cabe ainda salientar as limitações do estudo. Em primeiro lugar, a investigação cobriu uma única atividade de lazer e um único grupo de Seresta. Tal limitação é intrínseca ao método adotado, que não busca fazer generalizações para a população. Como observou Geertz (1973), a etnografia não estuda a aldeia, mas na aldeia. Nessa linha, o presente estudo utilizou o grupo de Seresta selecionado para realização do campo para entender aspectos relevantes de como os idosos reconstroem a Terceira Idade por meio do lazer em grupo. Em segundo lugar, é possível que a diferença de idade entre o observador participante e os informantes tenha, de alguma forma, produzido um viés. No entanto, dada a duração do período de observação, por um semestre, e a realização posterior das entrevistas, espera-se que tal viés tenha sido minimizado e que as falas dos entrevistados reflitam os significados atribuídos à atividade.

Por fim, o caráter interpretativo da pesquisa apontou caminhos que podem ser explorados em pesquisas futuras. Outras atividades de lazer em grupo foram citadas pelos idosos como viagens em grupo, saídas noturnas, participação em jogos e brincadeiras, aulas de teatro, entre outras. Essas atividades também podem ser analisadas a partir dos significados a elas atribuídos. Dado o relevo que o consumo de lazer possui no que tange à qualidade de vida e o bem-estar, pode-se investigar mais profundamente a relação de consumidores de lazer de outras faixas etárias. Esses estudos poderiam ajudar a aprofundar nuances do consumo do lazer, permitindo comparações entre os diferentes interesses dos grupos etários.

\section{REFERÊNCIAS}

Alexandris, K., \& Carroll, B. (1997). An Analysis of Leisure Constraints Based on Different Recreational Sport Participation Levels: Results from a Study in Greece. Leisure Sciences, 19 (1), 115.

Alves, A. M. (2007). Os Idosos, as Redes de Relações Sociais e as Relações Familiares. In: A. L. Neri (org.). Idosos no Brasil: Vivências, Desafios e Expectativas na Terceira Idade. São Paulo: Ed. Fundação Perseu Abramo, Edições SESC, 125-140.
Araujo, F. F., \& Chauvel, M. A. (2012). Marketing de cinema francês no Brasil: um estudo exploratório sobre as estratégias de promoção para o lançamento de filmes no mercado Brasileiro. Facef Pesquisa, v. 15 (3), 298-315.

Araujo, F. F., Rocha, A., Chauvel, M. A., \& Schulze, M. F. (2013). Meanings of Leisure among Young Consumers of a Rio de Janeiro Low-Income Community. Leisure Studies, 32 (1), 319-332.

Araujo, F. F., Casotti, L. M., Silva, R. C. M., \& Pessôa, L. A. G. P. (2015). O Consumidor de Terceira Idade na Primeira Década do Século XXI: Uma Análise da Propaganda Dirigida a Idosos. Revista Administração em Diálogo - RAD, 17 (1), 54-85.

Abep - Associação Brasileira de Empresas de Pesquisa. (2013). Critério de Classificação Econômica Brasil. Recuperado em 17, outubro, 2014 , de <http://www.abep.org/criterioBrasil.aspx $>$.

Ballstaedt, A. L. M. P. (2007). Comportamento e Estilo de Vida da População Idosa e seu Poder de Consumo. Anais do II Encuentro Latinoamericano de Diseño. Facultad de Diseño y Comunicación: Universidad de Palermo, Buenos Aires.

Barnhart, M., \& Peñaloza, L. (2013). Who Are You Calling Old? Negotiating Old Age Identity in the Elderly Consumption Ensemble. Journal of Consumer Research, 39 (6), 1133-1153.

Bauman, Z. (2005). Identidade. Entrevista Concedida a Benedectto Vecchi. Rio de Janeiro: Jorge Zahar.

Brakus, J. J., Schmitt, B. H., \& Zarantonello, L. (2009). Brand Experience: What is it? How Is It Measured? Does it Affect Loyalty? Journal of Marketing, 73 (1), 52-68.

Burnett-Wolle, S., \& Godbey, G. (2007). Refining Research on Older Adults' Leisure: Implication of Selection, Optimization, and Compensation and Socioemotional Selectivity Theories. Journal of Leisure Research, 39 (3), 498513.

Colbert, F. (2012). Marketing Culture and the Arts. $4^{\mathrm{a}}$. Ed. Quebec: HEC Montréal.

Cole, C., Laurent, G., Drolet, A., Ebert, J., Gutchess, A., Lambert-Pandraud, R., Mullet, E., Norton, M., \& Peters, E. (2008). Decision Making 
and Brand Choice by Older Consumers. Marketing Letters, 19 (3/4), 355-365.

Cotte, J., \& Kistruck, G. (2006). Discerning Marketers' Meaning: Depth Interviews with Sales Executives. In: R. W. Belk (org.). Handbook of Qualitative Research Methods in Marketing. Cheltenham: Edward Elgar.

Coupland, N., Coupland, J., \& Giles, H. (1991). Language, Society and the Elderly. Cambridge: Blackwell.

Crawford, D. W., Jackson, E. L., \& Godbey, G. (1991). A Hierarchical Model of Leisure Constraints. Leisure Sciences, 13 (1), 309-320.

Cuddy, A. J. C., Norton, M. I., \& Fiske, S. T. (2005). This Old Stereotype: The Stubbornness and Pervasiveness of the Elderly Stereotype. Journal of Social Issues, 61 (2), 267-285.

Cumming, E., \& Henry, W. E. (1961). Growing Old: The Process of Disengagement. New York: Basic.

Diniz, F., \& Motta, P. C. (2006). Em Busca de um Modelo de Restrição ao Lazer para os Consumidores de Mais Idade. Anais do Encontro Nacional da Associação de Pós-Graduação em Administração. Salvador, BA, Brasil, 30.

Doll, J. (2007). Educação, Cultura e Lazer: Perspectivas de Velhice Bem-Sucedida. In A. L. Neri (org.). Idosos no Brasil: vivências, desafios e expectativas na Terceira Idade. São Paulo: Ed. Fundação Perseu Abramo, Edições SESC, 109-124.

Dumazedier, J. (1973). Lazer e Cultura Popular. São Paulo: Perspectiva.

Elliott, R., \& Jankel-Elliott, N. (2003). Using Ethnography in Strategic Consumer Research. Qualitative Market Research, 6 (4), 215-223.

Esteves, P. S. (2010). O Papel das Emoções no Processo Decisório de Escolha de Destinos de Viagens por Consumidores da Terceira Idade. Dissertação de Mestrado. Universidade Federal do Rio Grande do Sul. Porto Alegre, RJ, Brasil.

Firat, F. A., \& Venkatesh, A. (1995). Liberatory Postmodernism and the Reenchantment of Consumption. Journal of Consumer Research, 22 (3), 239-267.
Fleischer, A., \& Pizam, A. (2002). Tourism Constraints among Israeli Seniors. Annals of Tourism Research, 29 (1), 106-123.

Fox, M. C., Roscoe, A. M., \& Feigenbaum, A. M. (1984). A Longitudinal Analysis of Consumer Behavior in the Elderly Population. Advances in Consumer Research, 11 (1), 563-568.

Geertz, C. (1973). A Interpretação das Culturas. Rio de Janeiro: Zahar.

Gergen, K., \& Gergen, M. M. (2000). The New Aging: Self-Construction and Social Values. In: K. W. Schaie \& J. Hendrick. The Evolution of the Aging Self: The Societal Impact on the Aging Process. New York: Springer, 281-306.

Gilly, M. C.; \& Enis, B. M. (1982). Recycling the Family Life Cycle: A Proposal for Redefinition. Advances in Consumer Research, 9 (1), 271-276.

Gilly, M. C., \& Zeithaml, V. A. (1985). The Elderly Consumer and Adoption of Technologies. Journal of Consumer Research, 12(3), 353-357.

Guido, G., Capestro, M., \& Peluso, A. M. (2007). Experiential Analysis of Consumer Stimulation and Motivational States in Shopping Experiences. International Journal of Market Research, (49) 3, 365-386.

Havlena, W. J., \& Holak, S. L. (1991). "The Good Old Days": Observations on Nostalgia and Its Role in Consumer Behavior. Advances in Consumer Research, 18 (1), 323-329.

Hoeymans, N., Feskens, E. J. M., Van Den Bos, G. A. M., \& Kromhout, D. (1997). Age, Time, and Cohort Effects on Functional Status and SelfRated Health in Elderly Men. American Journal of Public Health, 87 (10), 45-78.

Holbrook, M. B. (2006). Photo Essays and the Mining of Minutiae in Consumer Research. In: R.W. Belk (org.). Handbook of Qualitative Research Methods in Marketing. Cheltenhan: Edward Elgard Publishing Limited, 476-493.

Holbrook, M. B., \& Hirschman, E. C. (1982). The Experiential Aspects of Consumption: Consumer Fantasies, Feelings and Fun. Journal of Consumer Research, 9 (1), 132-140.

Holbrook, M. B. \& Schindler, R. M. (1994). Age, Sex and Attitude toward the Past as Predictors of Consumers' Aesthetic Tastes for Cultural 
Products. Journal of Marketing Research, 31 (3), 412-422.

Holt, D. B. (2002). Why Do Brands Cause Trouble? A Dialectical Theory of Consumer Culture and Branding. Journal of Consumer Research, 29 (1), 70-90.

Horneman, L., Carter, R. W., Wei, S., \& Ruys, H. (2002). Profiling the Senior Traveler: an Australian Perspective. Journal of Travel Research, 41 (1), 23-37.

Jodelet, D. (1989). Folies et Représentations Sociales. Paris: Presses Universitaires de France.

Kennett, P. A., Moschis, G. P., \& Bellenger, D. N. (1995). Marketing Financial Services to Mature Consumers. Journal of Services Marketing, 9 (2), 62-72.

Kohlbacher, F. (2006). The use of qualitative content analysis in case study research. Forum: Qualitative Social Research, 7 (1), art. 1.

Lambert-Pandraud, R., \& Laurent, G. (2010). Why Do Older Consumers Buy Older Brands? The Role of Attachment and Declining Innovativeness. Journal of Marketing, 74 (5), 104-121.

Mattila, M., Karjaluoto, H., \& Pento, T. (2003). Internet Banking Adoption Among Mature Customers: Early Majority or Laggards? Journal of Services Marketing, 17 (5), 514-528.

Moschis, G. (2003). Marketing to Older Adults: an Updated Overview of Present Knowledge and Practice. Journal of Consumer Marketing, 20 (6), 516-525.

Murphy, P. E., \& Staples W. A. (1979). A Modernized Family Life Cycle. Journal of Consumer Research, 6 (1), 12-22.

Myers, H., \& Lumbers, M. (2008). Understanding Older Shoppers: a Phenomenological Investigation. Journal of Consumer Marketing, 25 (5), 294-301.

Nasco, S. A., \& Hale D. (2009). Information Search for Home, Medical, and Financial Services by Mature Consumers. Journal of Services Marketing, 23 (4), 226-235.

Neugarten, B. L. (1968). Middle Age and Aging. Chicago: University of Chicago Press.
Pak, C., \& Kambil, A. (2006). Over 50 and Ready to Shop - Serving the Aging Consumer. Journal of Business Strategy, 27 (6), 18-28.

Peter, J. P., \& Olson, J. C. (2009). Comportamento do Consumidor e Estratégia de Marketing. São Paulo: McGraw-Hill.

Pettigrew, S., Mizerski K., \& Donovan, R. (2005). The Three "Big Issues" for Older Supermarket Shoppers. Journal of Consumer Marketing, 22 (6), 306-312.

Pine II, B. J., \& Gilmore, J. H. (1998). Welcome to the experience economy. Harvard Business Review, July-August, 97-105.

Provonost, G. (2011). Introdução à Sociologia do Lazer. São Paulo: Ed. Senac.

Schewe, C., \& Carlson, B. (2003). Age Matters: Segmenting Swedish Markets by Generational Cohorts. Lund Institute of Economic Research. Working Paper Series. Sweden: Institute of Economic Research of Lund University. ISSN 1103-3010.

Schindler, R. M., \& Holbrook, M. B. (2003). Nostalgia for Early Experience as a Determinant of Consumer Preferences. Psychology \& Marketing, 20 (4), 275-302.

Schmitt, B. H. (2001). Marketing Experimental. $1^{\mathrm{a}}$ Ed. São Paulo: Nobel.

Searle, M. S., Mahon, M. J., Iso-Ahola, S. E., Sdrolias, H. A., \& Van Dyck, J. (1998). Examining the Long Term Effects of Leisure Education on a Sense of Independence and Psychological WellBeing among the Elderly. Journal of Leisure Research, 30 (3), 331-340.

Sherry, J. F. (2006). Fielding Ethnographic Teams: Strategy, Implementation and Evaluation. In: R. W. Belk (org.). Handbook of Qualitative Research Methods in Marketing. Cheltenhan: Edward Elgard Publishing Limited, 335- 344.

Vargo, S. L., \& Lusch, R. F. (2004). Evolving to a New Dominant Logic for Marketing. Journal of Marketing, 68 (1), 1-17.

Venkatesh, U. (2006). Leisure: Meaning and Impact on Leisure Travel Behavior. Journal of Services Research, 6 (1), 87-108.

Ward, J. C., \& Reingen, P. H. (1990). Sociocognitive Analysis of Group Decision Making 
among Consumers. Journal of Consumer Research, 17 (3), 245-262.

Wells, W. C., \& Gubar G. (1966). Life Cycle Concept in Marketing Research. Journal of Marketing Research, 3 (4), 355-363.

Williams, P., \& Drolet, A. (2005). AgeRelated Differences in Responses to Emotional Advertisements. Journal of Consumer Research, 32 (3), 343-354.

Yin, R. K. (2005). Estudo de Caso: Planejamento e Método. $3^{\mathrm{a}}$ ed. Porto Alegre: Bookman. 